\title{
Redes Sociais Virtuais: um espaço para efetivação da aprendizagem cooperativa
}

\author{
Joicemegue Ribeiro Machado ${ }^{1}$ \\ Ana Vilma Tijiboy ${ }^{2}$
}

\section{Resumo:}

Este artigo $^{3}$ pretende trazer uma contribuição para o campo educacional através da análise das relações sociais provenientes da criação e proliferação das comunidades virtuais. Com isso busca-se lançar um olhar sobre estas redes virtuais como espaços de construção e produção de discursos, manifestação das múltiplas "verdades" sociais e suas representações. Para a operacionalização do trabalho foi realizada uma cartografia de diferentes softwares sociais, onde foram analisadas as produções narrativas veiculadas nas comunidades virtuais e realizadas entrevistas com professores dos ambientes informatizados de escolas particulares de Porto Alegre com o objetivo de analisar os softwares sociais e suas possibilidades de uso em educação.

Palavras-chave: redes sociais, comunidades virtuais, softwares sociais

\section{Abstract:}

This work pretends to contribute to the educational area through the analysis of social relations in virtual communities. Thus, these virtual networks are seen as a field of construction and production of discourses, reflecting the multiple social "truths" and its representations. To do so a cartography of different social software was done and the narratives were analyzed linked to virtual communities. Besides, teachers from private schools of Porto Alegre were interviewed with the objective to analyze the social software and its possibilities for educational settings.

Key-words: Social networks; virtual communities, social software

\footnotetext{
${ }^{1}$ Licenciada em pedagogia, especialista em Orientação Educacional (FAPA) e em Informática aplicada à Educação (ESPIE/UFRGS, 2003), trabalha com assessoria à implantação de ambientes informatizados em estabelecimentos de ensino. Atualmente cursa pós-graduação em Educação Ambiental pelo SENAC. E-mail: joicemegue@terra.com.br

2 Socióloga (UFRGS), mestre em Educação (Stanford University), doutora em Informática na Educação (PGIE/UFRGS, 2001), coordenadora do Núcleo de Apoio a Pessoas com Necessidades Educacionais Especiais (NAPNES/UFRGS) e professora no Curso de Especialização em Informática Aplicada à Educação da UNISC e no Curso de Pedagogia da UERGS. e-mail: anatiji@etcom.ufrgs.br

${ }^{3}$ Este artigo baseia-se na monografia apresentada como trabalho de conclusão do curso de Pós-Graduação e Especialização em Informática na Educação (UFRGS, turma 2003), intitulado Orkut: Uma Análise sobre as Redes Sociais Virtuais.
} 
A idéia de rede ${ }^{4}$ surge como uma grande metáfora que representa os tempos atuais e que precisa ser analisada e melhor compreendida. Essa forma de organização vem conquistando novos espaços e formas de agir baseadas na colaboração e cooperação entre os segmentos envolvidos. Nestas últimas décadas tem crescido o movimento de atuação em redes através de múltiplas iniciativas de colaboração solidária em nossa sociedade, como por exemplo: Conselhos Participativos, Rede Brasileira de Educomunicação Socioambiental, Associação dos Deficientes Físicos de Alvorada (ADAFA), Sistemas Locais de Troca (SEL), Sistemas Comunitários de Intercâmbio (SEC), Autogestão de Empresas pelos Trabalhadores, Cooperativa Mista de Consumo, produção e trabalho Compras Coletivas Ltda., difusão de Softwares Livres (Free Softwares), entre outros. Neste trabalho o enfoque recai sobre os softwares sociais, com suas ferramentas voltadas para formação de comunidades virtuais e a valorização dos laços interpessoais.

Com o desenvolvimento das ferramentas tecnológicas, principalmente aquelas promovidas pelo advento da Internet, emergem em nossa sociedade novas formas de relação, comunicação e organização das atividades humanas, entre elas, merecem destaque o estudo de redes sociais virtuais. As redes sociais apoiadas por computadores utilizam-se de diferentes recursos, entre eles: e-mails, fóruns, listas de discussão, sistemas de boletins eletrônicos (BBSs), grupos de notícias, Chats, Softwares Sociais como Orkut, Muvuca etc.

A formação de redes de interação vem atingindo as mais diversas esferas e campos de conhecimento, desde o plano econômico, científico, cultural etc. No campo econômico, a exploração do nicho social networking passa a ser alvo de interesse de empresas que estão vendo no ramo das redes sociais virtuais um amplo espaço para negociação de produtos e serviços e, enxergando também, o potencial de relacionamentos estabelecidos nas comunidades como forte capital social da atualidade. Além disso, a comunicação em rede tem sido explorada como instrumento de ativação de movimentos sociais e culturais como a luta dos direitos humanos, feministas, ambientalistas, etc. Na educação, a participação em comunidades virtuais ${ }^{5}$ de debate e argumentação encontra um campo fértil a ser explorado. Através dessa complexidade de funções, percebe-se que as redes sociais virtuais são canais de grande fluxo na circulação de informação, vínculos, valores e discursos sociais, que vem ampliando, delimitando e mesclando territórios. Entre desconfiados e entusiásticos, o fato é que as redes sociais virtuais são convites para se repensar as relações em tempo pós-modernos.

Apesar de uma grande massa não fazer parte desse mundo digital, o número de conectados cresce a cada dia e a participação em comunidades virtuais tem se tornado um hábito no cotidiano dos internautas. A expressão comunidade virtual passa a ser popularizada através do trabalho do jornalista americano Rheingold (1996, p.20) e serve para designar grupos de pessoas que se relacionam no ciberespaço através de laços sociais, onde hajam interesses compartilhados, sentimento de comunidade e perenidade nas relações:

\footnotetext{
${ }^{4} \mathrm{~A}$ arquitetura das relações em redes emerge na sociedade contemporânea como uma nova forma de relação distribuída, conectando diferentes elementos numa teia dinâmica e diferindo do antigo modelo de relações hierarquizadas. Essas formas vêm conquistando novos espaços e formas de agir baseadas na colaboração e cooperação entre os segmentos envolvidos. Em estruturas em forma de redes, os relacionamentos se configuram de forma não hierárquica (poder diluído), funcionando como um sistema descentralizado, complexo, híbrido, com alto grau de autonomia, facilitador da criação de novas ordens e formas, baseado em auto-regulações, com estímulo a multi-lideranças.

${ }^{5}$ Uma comunidade virtual surge a partir da iniciativa de um agente articulador, que pode ser um indivíduo, associação ou organização, que dará o impulso inicial a formação do grupo captando agentes que participarão do jogo em questão, num verdadeiro sistema de nodos e elos em movimento. Cada comunidade terá uma configuração particular segundo seus propósitos. Além dos valores e objetivos compartilhados, a dinamicidade vai depender da atuação e disponibilidade dos sujeitos envolvidos nas discussões. 
As comunidades virtuais são agregados sociais que surgem na (Internet), quando uma quantidade suficiente de pessoas leva adiante essas discussões públicas durante um tempo suficiente, com suficientes sentimentos humanos como para formar redes de relações pessoais no espaço cibernético.

Do mesmo modo que Rheingold, o autor e cientista espanhol Castells (1999, p.385) refere-se à comunidade virtual "como uma rede eletrônica de comunicação interativa autodefinida, organizada em torno de um interesse ou finalidade compartilhados, embora algumas vezes a própria comunicação se transforme no objetivo". Ele afirma que o desenvolvimento tecnológico fornece um suporte apropriado para a comunicação, favorecendo a desnacionalização e desestatização da informação.

Como vimos, a interação é uma condição para que haja uma construção social nessas redes. Entre os elementos importantes para que a relação na comunidade virtual se mantenha encontramos a motivação, tempo disponível e envolvimento das pessoas em torno dessas discussões, permanência, domínio técnico mínimo para utilização dos recursos e estabelecimento de comunicação, modo contrário, essas experiências podem assumir um caráter totalmente efêmero e desterritorializado, visto apenas como um lugar de passagem sem qualquer vínculo. Isto pode ser percebido em algumas listas de discussões e fóruns, onde o fluxo de mensagens encontra sentido quando há uma certa assiduidade das trocas entre os membros.

\section{Softwares Sociais: a Construção de Discursos e Produção de "Verdades"}

Os softwares sociais são programas que funcionam como mediadores sociais e que favorecem a criação de redes de relacionamentos através de espaços onde o usuário pode juntar pessoas do seu círculo de relacionamentos, conhecer outras que compartilhem os mesmos interesses e discutir temas variados, construindo diferentes elos entre os "eus" privado e público. Vale salientar que estes canais de comunicação e seus suportes tecnológicos, embora necessários para o funcionamento das trocas comunicativas, não podem ser confundidos como sendo a própria comunidade virtual. No ramo das redes sociais surgem os softwares sociais que funcionam como um sistema orgânico que reúnem diversas comunidades virtuais.

Para fazer um reconhecimento deste campo emergente foi realizada uma análise cartográfica de diferentes softwares sociais, entre eles: Orkut, Multiply, Wallop, SixDegrees, Berkzter, Temansters, Wowfriends, Dotnode, Recomendado, Muvuca, Mell, 1grau, NetQI, Meu amigo, Colegas, Hi5, Friendster, Stoodent, Kibop, Ilook, Tribe, Linkedin, Ezboard, Ecademy, Every One's, Icq Universe, Ryze, Pinoyster, Zorpia, Icufriends, Dogster, Catster, Mediaches e Sexkut ${ }^{6}$.

Esses softwares sociais funcionam a partir do cadastramento de um usuário que convida amigos ou outros usuários para participarem; esses, por sua vez, fazem o mesmo e, assim por diante, formando uma rede de conhecidos entre si. Alguns desses sites só aceitam novos associados mediante indicação, outros cobram pela utilização de alguns serviços. Cada software destes desenvolve recursos e serviços diferentes para formar suas redes segundo objetivos específicos. A grande parte destes ambientes empregam recursos como: pequeno blog onde pode deixar impressões pessoais, álbum de fotos, galeria de amigos, comunidades das quais o usuário pertence, correio, fóruns, destaque para os aniversariantes do mês na página inicial, alguns utilizam-se de ferramentas de utilização síncronas como identificador de quem está conectado naquele momento, com possibilidade de trocas de mensagens instantâneas, etc. Esses softwares

\footnotetext{
${ }^{6}$ O Sexkut foi um trote lançado por Wagner Martins, webmaster do humor Cocadaboa, sendo que no segundo dia do boato, a página recebeu 1092 visitas de internautas. Maiores informações também podem ser encontradas em http://www.cocadaboa.com/archives/003976.php V. $3 \mathrm{~N}^{\circ} 1$, Maio, 2005
} 
se multiplicam a cada dia na WEB, em contínuo movimento de mudança, sendo a análise feita neste estudo no período específico de setembro a dezembro de 2004.

Observa-se nas redes agentes estratégicos que funcionam como dinamizadores do fluxo de informações e interconexões, que estimulam o debate, propõem, desafiam os demais membros do grupo chamando-os à participação e geram ou aliviam tensões na articulação das diferenças. Dentro deste fluxo caótico de conectividade, o poder de articulação se evidencia naqueles que possuem maior mobilidade e rapidez na relação de conexões, eles são chamados de hubs ${ }^{7}$, pessoas que ocupam uma posição dentro da rede com grande índice de contatos, capazes de atuar rapidamente neste mundo de compressão do espaço e dissolução de fronteiras. Alguns desses softwares mostram o mapeamento da rede, isto é, os graus de separação entre os usuários.

Uma das experiências mais conhecidas de mapeamento das redes sociais foi realizada em 1967, por Stanley Milgram, professor da Universidade de Harvard, nos Estados Unidos. O método criado por Milgram ficou conhecido como small-world ${ }^{8}$ (mundo pequeno) e tornou-se referência no estudo das redes sociais. Milgram enviou 160 cartas a moradores do Nebraska, escolhidos aleatoriamente e estes teriam a incumbência de fazer a sua carta chegar até um corretor de valores em Massachusetts, porém a carta seria retransmitida somente através de alguém conhecido. Das 160 cartas, 42 chegaram ao seu destino. Como resultado da experiência, Milgram descobriu que as cartas que chegaram ao destinatário passaram por uma média de apenas 5,5 intermediários. Vários outros testes foram baseados neste modelo, inclusive utilizando a Internet como meio de propagação e obtendo um número bem próximo ao que Milgram indicou. Esse mapeamento é baseado na matemática dos grafos ${ }^{9}$ e tem como objeto de estudo a estrutura de conexões das redes. Os números encontrados por Milgram na sua experiência, representam o que se denomina extensão característica de caminho: o número médio de conexões necessárias entre um ponto e outro ponto qualquer da rede.

As redes de relacionamentos virtuais visam impulsionar as relações humanas através da tecnologia. Castells (2002, p.445) apresenta uma análise sobre os múltiplos laços de sociabilidade existentes nas comunidades virtuais, citando o trabalho do pesquisador e sociólogo Barry Wellman sobre a classificação desses vínculos em fortes e fracos. Os laços fracos existentes entre conhecidos distantes, são considerados "úteis no fornecimento de informações e na abertura de novas oportunidades a baixo custo". Esses vínculos cibernéticos transcendem a distância, a baixo custo, geralmente apresentam uma natureza assíncrona, com propagação rápida da informação e favorecem afiliações múltiplas.

Segundo Martinho (2004), o potencial da rede está na capacidade de gerar conexão. Nas suas próprias palavras:

A densidade da rede não está relacionada diretamente ao número de pontos que a constituem, mas à quantidade de conexões que esses pontos estabelecem entre si. Esse é o aspecto mais importante e parece provar que a capacidade da rede ultrapassa em muito a mera soma de seus elementos.

Com o objetivo de verificar se existe uma relação sobre a densidade de conexões existentes nas redes sociais virtuais, se aumenta ou diminui conforme a faixa etária, foi

\footnotetext{
${ }^{7}$ De acordo com o cientista húngaro Barabási (1999), os hubs são uma característica das redes de topologia escalável, como a Internet. Diferente de uma rede randômica, a rede escalável está em constante crescimento através dos hubs, que são nós (nodes) que congregam o maior número de links.

${ }^{8}$ Essa teoria das conexões inspirou o filme conhecido por Seis Graus de Separação (1993), com Will Smith e Donald Sutherland.

${ }^{9}$ Teoria dos Grafos é um ramo da matemática que estuda as propriedades dos grafos. Grafos são um conjunto de pontos, chamados vértices (ou nodos), conectados por linhas, chamadas de arestas (ou arcos). 
utilizada neste trabalho, uma amostragem composta por cem usuários do Orkut ${ }^{10}$. Estes foram selecionados e divididos em duas categorias. A primeira composta por cinqüenta jovens de até vinte e quatro anos e a segunda por cinqüenta pessoas a partir de vinte e cinco anos. Foi constatado que o primeiro grupo apresenta uma rede constituída de uma média de duzentos e dois contatos por pessoa, enquanto o segundo grupo, a média observada caiu para setenta e dois. Para os mais jovens adolescentes, observa-se a tendência de maior quantidade de contatos via Internet. Cabe salientar que os jovens compõem a maior parte das presenças no Orkut, conforme gráfico de janeiro 2005, apresentado a seguir:

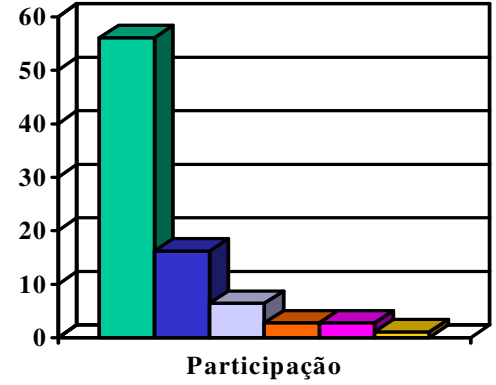

Percentual de usuários do Orkut por faixa etária

\begin{tabular}{|c|c|c|}
\hline & - idade & $\begin{array}{l}\text { - } \\
\text { cipaçãti }\end{array}$ \\
\hline$\bullet$ & 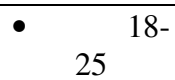 & - $\quad 8_{8 \%}^{56,0}$ \\
\hline & - $\quad 30^{26-}$ & - $\quad 5 \%{ }^{16,1}$ \\
\hline$\bullet$ & 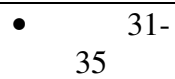 & - $\%^{6,44}$ \\
\hline • & - $40{ }^{36-}$ & - $\%^{2,76}$ \\
\hline$\bullet$ & $\begin{array}{l}\text { - } \quad 50 \\
\end{array}$ & - $\%^{2,25}$ \\
\hline$\bullet$ & $\begin{array}{lll} & & \\
& 50 & \end{array}$ & - $\%^{1,06}$ \\
\hline
\end{tabular}

Observar a rede crescendo faz parte de uma grande diversão, onde nesta abertura para novos relacionamentos todos são bem-vindos e linkados, desta forma tem-se a impressão que para esta geração a expressão "Link é poder" é um imperativo. Há vários recursos para facilitar o crescimento dos amigos, entre eles, ao navegar pelas páginas e ter acesso à rede dos amigos, podendo assim, encontrar conhecidos comuns com maior agilidade. $\mathrm{O}$ usuário conta também com um serviço de pesquisa que facilita a buscas de novos contatos através de nomes, endereços de e-mails ou características. Muitos desses sites oferecem espaços para comentários sobre os amigos, com possibilidade de adicionar-lhes status de "pessoas especiais", "conhecidos", "bons amigos" indicando diferentes graus de amizade. No Orkut, por exemplo, a classificação dos contatos pode ser feita através de um sistema de "cotações" ao lado do nome do usuário, onde três características são avaliadas: confiabilidade (smiles), o grau de sensualidade (corações) e simpatia (cubos de gelo - "cool”, em inglês). Há também, ferramentas que funcionam como uma agência de namoros. O usuário adiciona outro de seu interesse na lista secreta, e se aquele também tiver cadastrado na sua lista, ambos recebem um e-mail informando que o interesse foi correspondido. Caso isso não ocorra, é mantido segredo sobre o eleito.

Outra possibilidade é a de manter o anonimato. Esse mecanismo pode funcionar como um laboratório de autoconhecimento, facilitando a experimentação de outras formas de atuação no mundo, deixando aflorar desejos, fantasias e sentimentos contidos. A imagem como deslocamento de si mesmo para o espaço virtual favorece o brincar das

\footnotetext{
${ }^{10} \mathrm{O}$ site Orkut foi lançado em 22 de janeiro de 2004, sendo o engenheiro turco Orkut Büyükkokten o responsável pela criação desse sistema para a empresa norte-americana Google. Nos primeiros dias de fevereiro, 100 mil novos usuários haviam se cadastrado no sistema. No Brasil este fenômeno vem alcançando amplas escalas. No dia 28 junho, de acordo com a página de estatísticas do próprio Orkut, o número de brasileiros cadastrados foi de $32,9 \%$, ultrapassando a presença de usuários norte-americanos que era de $28,67 \%$, apesar do site usar a língua inglesa. Em 03 de janeiro de 2005, quase concluindo um ano de atividade, os brasileiros eram $62,13 \%$ da rede, enquanto os americanos apenas $38,6 \%$.

V. $3 \mathrm{~N}^{\circ} 1$, Maio, 2005
} 
formas. Cada foto representa marcas sempre muito pessoais. Os efeitos, cores, texturas recriam um novo aspecto da realidade que vai sendo modelada pelos recursos dos editores gráficos. A virtualização do corpo permite a exposição de partes (como as fotos que revelam apenas um olho ou a exposição de somente uma boca), ou distorções criativas através do sombreado que pouco deixa ver, enfim, artifícios digitais utilizados para explorar a categoria sexualidade. Estes espaços também pode ser utilizados na criação de outras identidades possíveis. Ser um outro, não um outro diferente de mim, mas como negação do que sou e que agora se manifesta, o meu outro possível. Quantos "outros" podem emergir de nós mesmos? A rejeição torna-se menos dolorida, a timidez encontra a ousadia, a feiúra transforma-se em beleza, é possível experimental novas sensações quando se está protegido através de alguma máscara virtual.

Felinto (2002, p. 22) comenta que no mundo virtual, a identidade passa a ser fruto de um processo de construção intencional, e, desse modo, os sujeitos teriam total liberdade na reelaboração de suas personas. "O sujeito passa a ser criador de si mesmo; demiurgo que produz não apenas novos mundos e seres, mas que também pode recriarse indefinitivamente". Rompe-se assim com o paradigma da identidade única e determinada, que busca com a modernidade classificar cada um no seu lugar, colocar uma etiqueta e catalogar. A identidade passa a metamorfosear-se, aparecer em sua multiplicidade, evidenciando o ser complexo dos novos tempos, fragmentado.

Nos softwares sociais, as comunidades funcionam como uma moderna lista de discussão, porém mais personalizada, no qual os laços sociais (os amigos/friends) agenciam e potencializam as conexões de cada um com todos os demais, onde as normas são definidas de acordo com valores criados pelos próprios integrantes em um sistema auto-regulado. Esta grande rede cooperativa que se distribui rizomaticamente e de forma imprevisível, gera espaços de construção de subjetividades e de possíveis tensões sociais. Essa idéia de imprevisibilidade não é apenas uma questão de desordem e de caos, mas sim, a própria representação da diversidade e complexidade humana. Ao mesmo tempo em que valoriza o individual dentro da coletividade, favorece a percepção de conexão planetária, de que todos, de uma certa forma, estão conectados uns aos outros por laços relacionais. Essa idéia de pertencimento a um todo maior pode ser explorada para o desenvolvimento de novas práticas relacionais de solidariedade, cooperação, envolvimento e responsabilidade sobre o todo. Um dos desafios deste mundo globalizado está em como, nessa grande massificação, ser reconhecido como sujeito com identidades e necessidades específicas. Nunca houve tanto espaço de luta para o reconhecimento de identidades como atualmente através dos movimentos da identidade negra, homossexual, feminista etc. Afinal, é no confronto da heterogeneidade, na interação com o outro, que o ser humano é capaz de se descentralizar e transitar numa zona coletiva. Os agenciamentos coletivos das vontades são sempre processos complexos que visam a conquista do prazer e da auto-realização, resultando no jogo intricado de negociações, tensionamentos e poder. Essas permutas fazem parte do exercício de autonomia e ética, que priorizam relações mais autônomas. Os softwares sociais são mais um recurso para a construção de discursos e produção "verdades sociais". Ainda não está desvelado o fim e potencial dessas grandes redes sociais virtuais, mas sem dúvida elas afetam e promovem modos de relação.

\section{Conectando Saberes para além da Escola}

As novas tecnologias de informação e comunicação chegam à escola, muitas vezes como uma imposição da modernidade, sem saber bem o seu lugar neste ambiente e acabam esquecidas ou "escolarizadas" - com a missão de resolver as tarefas 
educacionais propostas. Os professores sentem-se na obrigação de utilizar esses aparatos tecnológicos, mas muitas vezes não tem formação, assistência técnica ou apoio da estrutura escolar na organização dos tempos e espaços de utilização dos mesmos em seus planejamentos. Esse quadro acaba resultando em um grande investimento de recursos públicos na compra de equipamentos que acabam sucateados em laboratórios de informáticas, trancados ou subutilizados, gerando aquilo que Winner (1987) chama de sonambulismo tecnológico, isto é, quando a sociedade se submete humildemente a cada nova exigência da tecnologia e utiliza sem questionar todo o produto, seja ele positivo ou negativo para uma melhora real. Essa não apropriação dos recursos, principalmente no aproveitamento de suas potencialidades, acaba construindo uma imagem de que a escola é desconectada do mundo existente fora dos seus portões.

Nas entrevistas realizadas com seis professores responsáveis pelos ambientes informatizados de diferentes escolas de Porto Alegre foi diagnosticado que durante o ano de 2004, nenhuma delas trabalharam com softwares sociais. Numa das escolas, $75 \%$ do corpo docente já ouviu falar sobre algum deles, principalmente o Orkut que foi muito divulgado pela mídia e porque também, alguns professores ficaram sabendo através de seus filhos adolescentes que participam dessas redes. Nessa mesma escola, apenas a professora do ambiente informatizado participa de um desses sites, mas não vê aplicação desse instrumento com os alunos, dizendo que na sua escola já foram tomadas medidas de segurança como a colocação de filtros para que os alunos não acessassem esses sites e outras ferramentas de comunicação. $\mathrm{O}$ argumento utilizado para justificar a utilização desses mecanismos de controle foi "por medidas seguras contra nazismo e pedofilia" ou demais assuntos proibidos que circulam na rede.

Ficam aqui alguns pontos de reflexão: ao evitar lidar com os acontecimentos do mundo, a escola não estaria deixando vazio o espaço da discussão e reflexão com os alunos, que vão acabar se deparando com estas questões no seu cotidiano? Será que a escola deve aderir a os softwares sociais apenas por estes terem recebido grande destaque na mídia? Ou ainda, esses softwares são para serem usados para fora da escola, afinal trabalho é trabalho e não se tem tempo para perder com estas bobagens? Esse é um campo de negociações e de poderes, mas quem decide o que cabe à escola? Se a escola reconhecer que a disseminação da informação não é mais responsabilidade apenas sua, que a troca de saberes pode se dar de maneira autônoma através da cooperação mediada pelas novas tecnologias de informação e comunicação, como fica o seu papel enquanto lugar de construção dos conhecimentos? Talvez seja esse um dos grandes desafios da escola neste mundo globalizado, como lidar com essa circulação de saberes que transcendem os muros da escola. Para romper com este enclausuramento ${ }^{11}$, dentro de uma perspectiva holística, a escola necessita abrir espaço para o respeito à diversidade e para a conexão dos diversos saberes existentes através de redes de cooperação. Nesse sentido, os softwares sociais podem funcionar como um aliado, pois eles possibilitam o encontro de pessoas que tenham interesses similares e múltiplas visões, facilitando o estabelecimento da comunicação e ampliando as atividades de cooperação e reconhecimento do outro, o que implica numa mobilização coletiva, conforme nos mostra Lévy (1999, p. 30):

$\mathrm{Na}$ era do conhecimento, deixar de reconhecer o outro em sua inteligência é recusar-lhe sua verdadeira identidade social, é alimentar seu ressentimento e sua hostilidade, sua humilhação, a frustração de onde surge a violência. Em contrapartida, quando valorizamos o outro de acordo com o leque variado de seus saberes, permitimos que se identifique de um modo novo e positivo, contribuímos para mobilizá-lo, para

\footnotetext{
${ }^{11}$ Ver Michael Foucault em Vigiar e Punir, que trata sobre os mecanismos disciplinares, onde o enclausuramento mostra que cada indivíduo é colocado em seu lugar; e em cada lugar é colocado um indivíduo. 
desenvolver nele sentimentos de reconhecimento que facilitarão, consequentemente, a implicação subjetiva de outras pessoas em projetos coletivos.

Dessa forma, as redes sociais podem contribuir para a mobilização dos saberes, o reconhecimento das diferentes identidades e a articulação dos pensamentos que compõem a coletividade. Por isso é possível a escola fazer uso dessas redes sociais levando em consideração as intervenções intencionais dos professores, que podem funcionar como agentes capazes de contribuir para o aprofundamento das temáticas discutidas nesses espaços e orientar as discussões, auxiliando no aprofundamento dos temas, na síntese de idéias, no levantamento de aspectos significativos e nos secundários, na análise crítica dos dados.

Um dos conflitos que a escola pode enfrentar na utilização das redes sociais é o papel descentralizador que o professor deverá ocupar. Isso requer uma mudança de paradigmas de poder, se antes o professor tinha um controle maior sobre os saberes que circulavam na sala de aula, com esta nova possibilidade, perde o controle deste espaço e do grupo, não tendo mais um uma turma fixa de alunos, pois qualquer um pode participar do processo, bastando se logar à rede e interagir, em qualquer horário. Esse tipo de proposta exige maior autonomia por parte dos alunos e maior responsabilidade por assumir a direção das suas aprendizagens, tendo o professor como um agente coparticipante.

Este novo cenário pode parecer assustador para o professor, se já não é ele mais que "professa", ou seja, o que torna público, ou socializa algum conhecimento, qual o significado de sua função? Se não aprendemos apenas na escola, será que ainda haverá espaço para esta instituição num futuro próximo? Ao trabalhar com redes sociais virtuais, a educação seria de responsabilidade de todos para todos, num plano econômico de educação. Afinal, o uso dessas redes pode beneficiar ou aniquilar a educação formal? Haverá espaço para a co-existência ou aproveitamento dessas diferentes formas de aprendizagem? Até que ponto é vantajoso não permitir que estas formas de participação entrem na escola e libertem os alunos de todo aparato escolar?

Essas questões visam trazer novos significados e rupturas no campo educacional, principalmente no que se refere à abertura de seu currículo ${ }^{12}$ incitando a buscar outras formas de trilhar os caminhos da aprendizagem, pois quanto mais aberto for o currículo, maior será o espaço de circulação das múltiplas narrativas e de trocas efetivas. Este trabalho não tem a pretensão de esgotar o tema em questão, mas visa contribuir para discussões e reflexões acerca deste sistema complexo de redes sociais virtuais e sua possibilidade para fins educacionais.

As novas tecnologias de informação e comunicação podem auxiliar nessa caminhada, desde que não sejam utilizadas de maneira ingênua, numa versão escolarizada, baseada no sonambulismo tecnológico. A utilização desses recursos deve vir acompanhada, além de um mínimo domínio técnico, de uma visão histórica e social.

As redes sociais virtuais são recursos recentes nas sociedades informatizadas e requerem um olhar atento sobre suas possibilidades e alcances para a educação, devendo ser objeto de estudo em outras pesquisas para que se possa aprofundar e avançar em novas direções. Sabe-se que é um espaço de construção de identidades, de

12 O currículo aqui entendido como toda e qualquer ação da escola, ou seja, a forma como o espaçotempo é administrado, em seus recreios, períodos, calendários, disciplinas, conteúdos, séries, ciclos, atividades, avaliações, forma como as mesas e cadeiras estão distribuídas na sala e todas as nuances guiadas por questões sociológicas, políticas e epistemológicas que fazem parecer que esta é a ordem natural e indispensável de fazer as coisas. 
encontro e confronto com o outro, de produção de saberes, de circulação de valores e de pluralidades.

Pode ser utilizado pelas escolas para dar significado às experiências dos estudantes, serve como espaço público de discussão sobre os diferentes temas, propício para trabalhar as relações, laços afetivos, diagnosticar preferências, desenvolver o pensamento holístico, trabalhar a linguagem digital, deparar com posições conflitantes sobre os mais variados assuntos, trabalhar cooperativamente assuntos de interesse do aluno e inúmeras estratégias, de acordo com a criatividade e objetivos dos alunos e professores. Mas não cabe aqui trazer receitas didáticas sobre a integração das redes sociais virtuais na prática educativa. Mais do que utilizar o computador como ferramenta para educação, espera-se buscar alternativas tecnológicas que possam funcionar como mediadoras e transformadoras do processo educacional, permeadas por novas formas de sociabilidade. A conclusão deste texto é mais uma provocação, um convite para deixar sempre uma porta aberta para novos diálogos. Diálogos estes que nos permitam fazer uma leitura crítica e contextualizada do mundo. Fica para os educadores um diálogo inacabado a espera de co-autoria.

\section{Referências Bibliográficas}

CASTELlS, Manuel. A Sociedade em Rede - A era da informação: economia, sociedade e cultura; v. 1, 3a. Editora São Paulo, Paz e Terra, 1999.

CASTELLS, Manuel. A Era da Informação: o Poder da Identidade. São Paulo: Paz e Terra, 2002.

FELINTO, Erick. Tecnognose: tecnologias do virtual, identidade e imaginação espiritual. In Revista FAMECOS: mídia, cultura e tecnologia. EDIPUCRS. Porto Alegre, n. 18, p.15 - 25, agosto de 2002.

FOUCAULT, Michel. Vigiar e Punir: nascimento da prisão. $23^{\mathrm{a}}$ ed. Petrópolis. Vozes; 2000

LÉVY, Pierre - A inteligência Coletiva - por uma antropologia do ciberespaço. Edições Loyola, São Paulo, 1999.

MARTINHO, Cássio e COSTA, Larissa (coord.) Redes: Uma introdução às dinâmicas da conectividade e da auto-organização. WWF-Brasil. Disponível em $<$ http://www.wwf.org.br/publicacoes/download/livro_ea_redes/index.htm> Acesso em outubro de 2004.

RHEINGOLD, Howard. La Comunidad Virtual: Uma Sociedade sin Fronteiras. Gedisa Editorial. Colección Limites de La Ciência. Barcelona 1996. Também disponível em inglês em<http://www.rheingold.com/vc/book/ $>$.

WINNER, Langdon. La ballena y el reactor. Barcelona: Gedisa, 1987. 